\title{
The "Jeff Cut": A simple innovation to minimise up-riding sleeves of protective gown
}

\section{Dear Editor,}

Personal protective equipment (PPE) including the N95 mask, face shield, cap, splash-resistant gown and gloves are worn by frontline healthcare workers for various duties in the care of patients with communicable diseases like COVID-19. ${ }^{1,2}$ PPE is also worn by ancillary staff such as security personnel, porters, medical transport crew and cleaning staff who come into direct contact with infectious patients.

For protection to be optimal, the equipment has to fit properly. Otherwise, there will be breaches in protection leading to potentially serious consequences. For example, all personnel undergo a rigorous N95 mask fitting exercise before they are deployed to care for potentially infectious individuals.

The protective gowns that healthcare and other support workers in Singapore don during the COVID-19 pandemic ${ }^{3}$ may not be well-fitted to all individuals as the gown comes in 1 standard size. Cuffs that are too loose coupled with ill-fitting non-sterile gloves will result in up-riding of sleeves, leading to exposure of bare skin over the wrist, as exemplified in Fig. 1A.

Our medical team was deployed to a foreign worker dormitory from 12 April to 20 July 2020 under the National Healthcare Group's support of the dormitory medical operations during the COVID-19 outbreak in
Singapore. ${ }^{4}$ This deployment was part of the nationwide effort to provide adequate care to the huge number of infected foreign workers. ${ }^{5}$ At the end of the deployment period for our medical team on 21 July 2020, there was a cumulative total of 45,260 dormitory residents out of a total of 48,035 people who were reported as positive for COVID-19 in Singapore. ${ }^{7}$

A doctor from our team shared a technique to overcome this up-riding of the sleeve - a technique that was inspired by the design of commercially available arm sleeves for sports such as riding, which features a slot for the thumb. We term it the "Jeff Cut", and outline the following steps to achieve it.

Step 1. Before the gown is worn, cut a $1 \mathrm{~cm}$ slit at the midpoint of the non-seam side of the white cuff (Fig. 2).

Step 2. Don the splash-resistant gown and the non-sterile glove. The white cuff should cover the inner glove and the thumb should go through the slit (Figs. 3A and B). The first glove can be worn before or after donning the gown, depending on personal preference.

Step 3. Don the second glove to cover the junction (Figs. 3C and D).

The up-riding of the sleeve is now prevented by the grip of the cuff anchored at the base of the thumb as
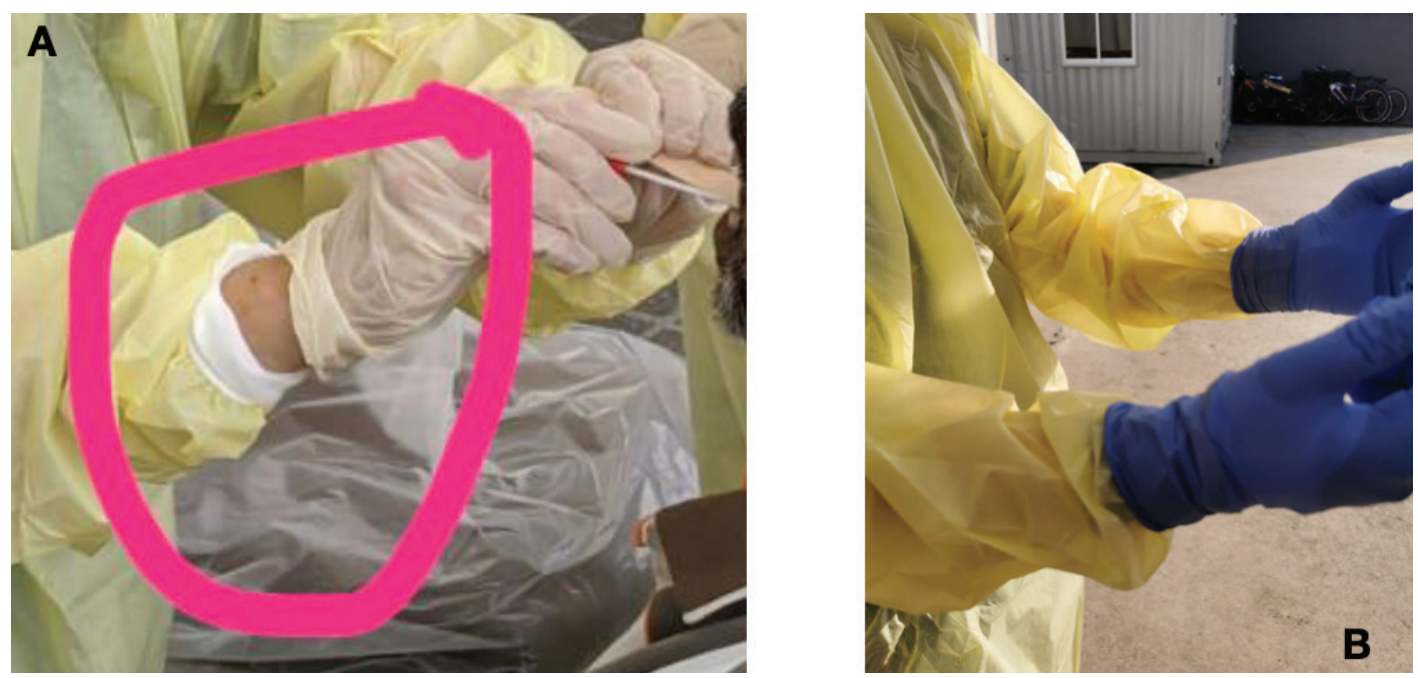

Fig. 1. (A) Up-riding of gown sleeve during a swabbing procedure. (B) Prevention of up-riding of sleeve suitable for any work posture. 


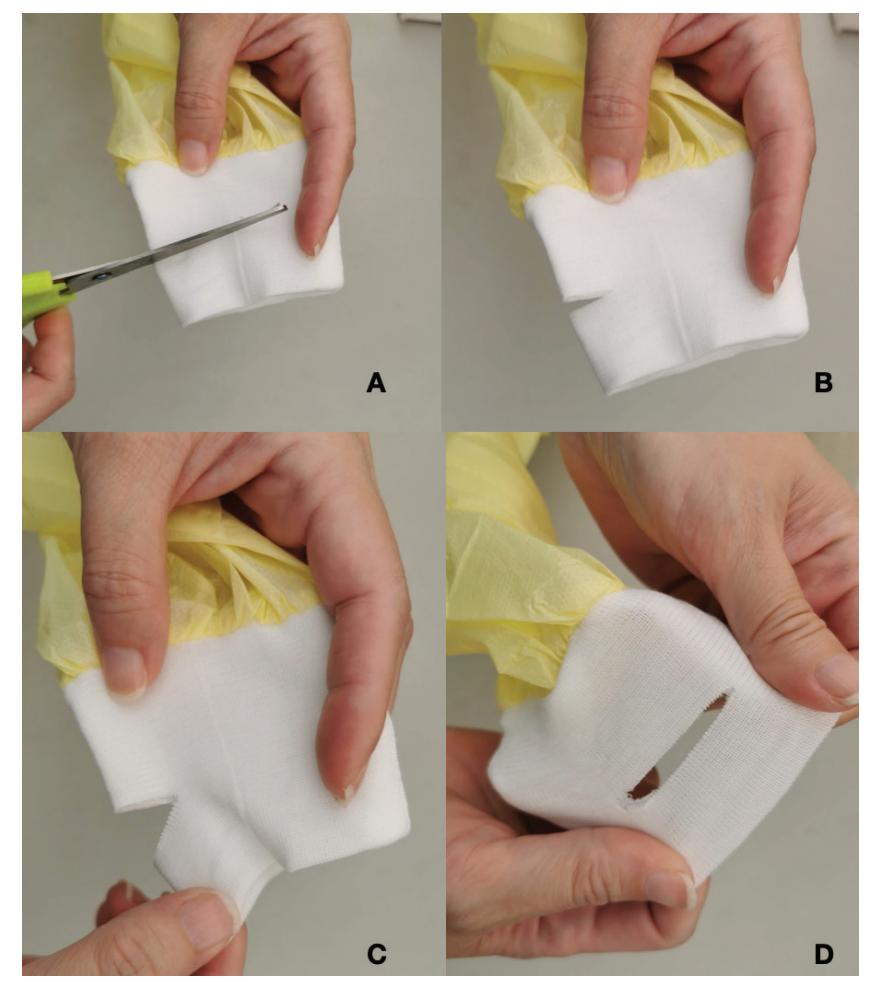

Fig. 2. Step 1 for the "Jeff Cut".

it emerges through the created slit (Fig. 1B), thus preventing a breach in the protective barrier.

In our experience, as the cuff was made of an elastic material, it did not tear easily — as long as the slit was made away from the seams - and we did not encounter any inadvertent exposure.

This method is simple and quick to execute. It utilises and enhances the safety of preexisting equipment and we recommend it to personnel who are required to don this in the course of their work.

\section{REFERENCES}

1. Verbeek JH, Rajamaki B, Ijaz S, et al. Personal protective equipment for preventing highly infectious diseases due to exposure to contaminated body fluids in healthcare staff. Cochrane Database Syst Rev 2020;5:CD011621.

2. Tan JL, Tay VS, Li H, et al. Otolaryngology Surgery in Time of COVID-19-What PPE to Use When? Ann Acad Med Singap 2020;49:387-92.

3. Hsu LY, Chia PY, Lim JF. The Novel Coronavirus (SARS-CoV-2) Epidemic. Ann Acad Med Singap 2020;49:105-7.

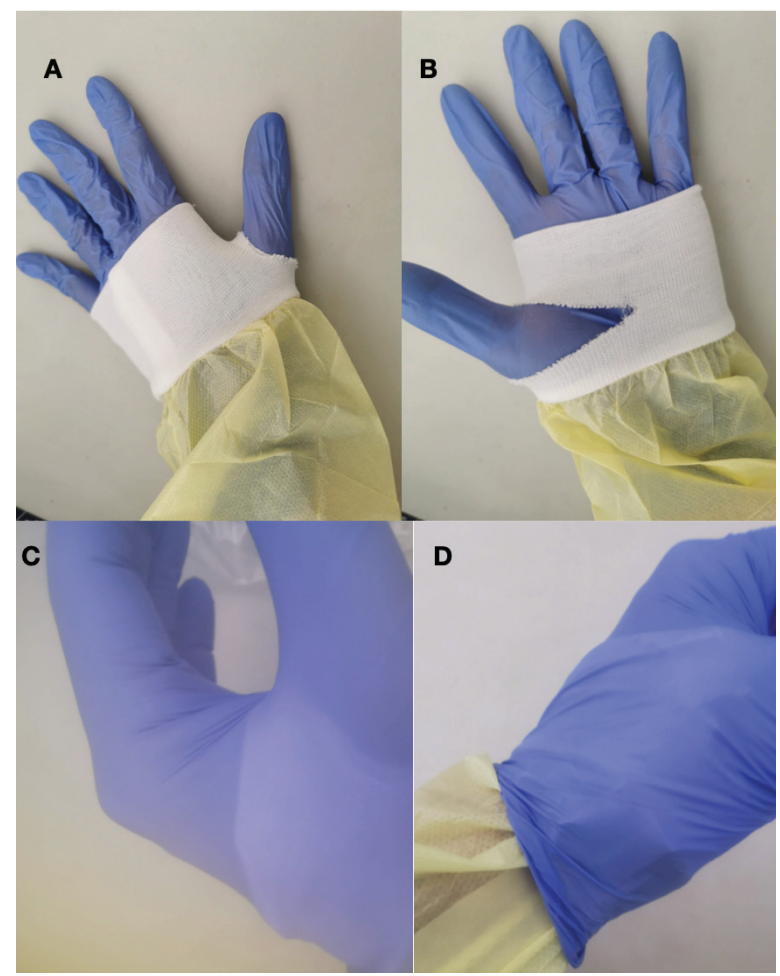

Fig. 3. Steps 2 and 3 for the "Jeff Cut".

4. The Straits Times. Coronavirus: 'Fast' teams in place at all 43 dormitories to tackle situation, 10 April 2020. Available at: https://www.straitstimes.com/singapore/fast-teams-in-place-at-all-43dormitories-to-tackle-situation. Assessed on 25 July 2020.

5. Lim TK. The Facts, Fallacies and Uncertainties about Coronavirus Disease 2019 (COVID-19). Ann Acad Med Singap 2020;49:343-5.

6. Ministry of Health, Singapore. Situation report - 20 July 2020. Available at: https://www.moh.gov.sg/covid-19/situation-report. Assessed on 25 July 2020.

Jeffrey Kah Leong Lum ${ }^{1}{ }^{M B B S}\left(S^{\prime}\right.$ pore),

Qi Wei Fong ${ }^{2} M B B S$ (S'pore), Shipei Law ${ }^{2} M D$,

Erik Sze Wee Ang ${ }^{3}$ FRCS (Glasg)

${ }^{1}$ OMF International, Singapore

${ }^{2}$ National Healthcare Group Polyclinics (Geylang Polyclinic), Singapore

${ }^{3}$ Yap \& Ang Surgical Associates, Farrer Park Medical Centre, Singapore

Correspondence: Dr Erik Sze Wee Ang, Yap \& Ang Surgical Associates, 1 Farrer Park Station Road, \#09-09 Farrer Park Medical Centre, Singapore 217562.

Email: angplasticsurgery@gmail.com 